\title{
Fernando Pessoa, herdeiro do mundo mágico As raízes ocultas da poética pessoana
}

\begin{abstract}
Resumo
Se é verdade que a Modernidade representa, na opinião de muitos, o triunfo do progresso científico e da razão, é também verdade que nos seus fundamentos se encontra uma visão mágica e irracional do mundo, de maneira alguma desaparecida da nossa cultura. O presente artigo divide-se em uma introdução às raízes ocultas da época moderna, nas suas facetas artísticas, filosóficas e literárias, em seguida focando a atenção na figura de Fernando Pessoa. O poeta português, de facto, é herdeiro direto de uma antiga Weltanschaunng mágica, que passa por Marsílio Ficino e Giordano Bruno, mas também por Johann Wolfang von Goethe e por Isaac Newton, para chegar a poetas modernos como William Butler Yeats e Thomas Stearns Elliot, mas também ao próprio Pessoa. A paixão do poeta pela astrologia, pela filosofia hermética e pelo ocultismo não era apenas um passatempo, mas uma verdadeira chave de leitura para compreender o mundo, interpretá-lo e reelaborá-lo através da criação poética.
\end{abstract}

Palavras-chave: astrologia; modernidade; mundo mágico; ocultismo; Fernando Pessoa.

\section{Riassunto}

Se è vero che la Modernità rappresenta per molti il trionfo del progresso scientifico e della ragione, è anche vero che alle sue fondamenta s'incontra una visione magica e irrazionale del mondo, tutt'altro che scomparsa dalla nostra cultura. Il presente articolo si divide in un'introduzione alle radici occulte dell'epoca moderna, nelle sue sfaccettature artistiche, filosofiche e letterarie, focalizzando in seguito l'attenzione sulla figura di Fernando Pessoa. Il poeta portoghese, infatti, è erede diretto di un'antica Weltanschaunng magica che passa da Marsilio Ficino e Giordano Bruno, ma anche da Johann Wolfang Von Goethe e Isaac Newton, per arrivare a poeti moderni come William Butler Yeats e Thomas Stearns Elliot, ma anche allo stesso Pessoa. La passione per l'astrologia, la filosofia ermetica e l'occultismo non era per il poeta un semplice svago da tempo libero, ma una vera e propria chiave di lettura per comprendere il mondo, interpretarlo e rielaborarlo attraverso la creazione poetica.

Parole chiave: astrologia; modernità; mondo magico; occultismo; Fernando Pessoa.
Rita Catania Marrone

Universidade de Coimbra 


\section{Introdução: as raízes ocultas da Modernidade}

Se quisermos encontrar duas figuras emblemáticas da entrada na Modernidade, deveríamos tomar em consideração Isaac Newton e Johann Wolfgang von Goethe. Embora vivos a uma distância de cem anos um do outro, uma perspectiva de história das ideias permite-nos considerar os dois cientistas como duas personagens paradigmáticas do nascimento da época moderna. A luta teorética entre Newton e Goethe, que bem se observa na disputa sobre a teoria das cores, pode revelar os dois pontos de vista diferentes que se enfrentaram na constituição da ciência como nós a conhecemos hoje. As duas perspectivas, a um primeiro olhar, parecem inconciliáveis: a vitória de Newton sancionou o triunfo de uma visão do mundo científica e analítica; enquanto a derrota simbólica de Goethe determinou a perda (pelo menos aparente, como veremos) de uma Weltanschaunng "holística", não reducionista. Os movimentos cognitivos que caracterizam os dois métodos são opostos: onde Newton divide e decompõe o fenómeno para encontrar a sua essência ("análise" significa etimologicamente "anàlysis", onde lyo em grego quer dizer "desatar"), Goethe faz exatamente o contrário, tentando remontar das partes para o todo que estas compõem.

O método de Goethe é evidente no ensaio sobre a metamorfose das plantas, Versuch die Metamorphose der Pflanzen zu erklären, de 1790. Na perspectiva goethiana, a natureza é uma totalidade dinâmica que, embora se renove, conserva a sua unidade originária. Existe um processo criador infinito que pode ser percebido a partir das suas manifestações específicas e o estudo das formas assumidas pela natureza nas suas metamorfoses toma o nome de morfologia. O papel da investigação morfológica é colher o eterno no devir, a unidade presente em todos os seus segmentos.

O olhar de Goethe, portanto, vê as partes dinâmicas como pertencentes a um Todo eterno, como em um mosaico em que cada fragmento contribui para a formação de uma imagem única e harmônica. Todavia, a sua pesquisa não é exclusivamente naturalística. O método morfológico compreende toda a constelação humana: os estudos científicos não devem ser separados dos estéticos e filosóficos. O pensador alemão propõe-se a desvelar a relação entre mundo da arte, da ciência e a dimensão existencial do Homem, pois uma filosofia que se quisesse dizer completa não poderia excluir nenhum campo da sabedoria.

Tal pensamento deriva da filosofia de matriz renascentista que não separa o Homem da natureza, pondo-o em uma posição privilegiada, mas considerando-o como parte integrante 
de um Todo em que se insere harmonicamente. Existe entre os entes uma harmonia cósmica, uma "significatividade universal"', ou seja, o universo é constituído por uma rede de forças que ligam todos os pontos entre si, doando-lhes sentido. Dessa forma, tudo adquire um valor enquanto participa do resto da criação. Portanto, também a nossa alma possui uma continuidade com o espírito do cosmos (como afirma, por exemplo, Giordano Bruno na obra De magia ${ }^{2}$ e, assim como a natureza e as esferas superiores seguem o curso das estacões, o nascer e o pôr do sol, as fases da lua, etc., nós também estamos submetidos às mesmas regras que determinam o movimento de cada coisa.

É através do conhecimento dos vínculos que unem todos os entes que o Ser humano pode operar de forma mágica, chegando a dominar a natureza (ainda Giordano Bruno, De vinculis in genere $^{3}$ ) e, pelo mesmo motivo, é possível a prática da astrologia, que lê nos astros o futuro do indivíduo. Como ensina uma máxima hermética, "o que está em baixo é como o que está em cima e o que está em cima é como o que está em baixo": existindo uma correspondência entre microcosmo e macrocosmo - isto é, o Homem e as esferas superiores do céu - é possível definir as influências astrais que determinam o decurso da vida de um indivíduo. Assim, o Homem pode espelhar-se nas estrelas, como as estrelas também se espelham no Homem.

Como afirma o filósofo italiano Paolo Rossi ${ }^{4}$, é recorrente o erro de julgar primitivas e supersticiosas as crenças do chamado mundo mágico, em vez de perceber que se trata apenas de uma Weltanschanung diferente, que não é superior ou inferior à científica, mas representa sim uma alternativa. Quando a filosofia da história de cunho iluminista estabeleceu que a marca distintiva da Humanidade é o progresso, esqueceu-se que cada mudança na história do pensamento implica uma perda. Ganhando Newton a luta contra Goethe - que neste ensaio tomamos como um dos últimos exponentes e herdeiros do mundo renascentista -, o Homem perdeu o seu lugar harmônico dentro da natureza, de que já não é filho mas sim dono presunçoso, e deixou de olhar para o universo e reconhecer-se nas estrelas.

Existiu (e ainda existe) uma maneira alternativa de perceber a história, que não é a religião do progresso a qualquer preço, mas sim a procura de uma sabedoria originária e ancestral que ficou perdida no decurso dos tempos e que é preciso renovar e redescobrir. Um movimento, portanto, que não olha para a frente tendo em vista um melhoramento, mas que volta para trás, à procura de algo de que se esqueceu. Alguns leitores ficarão surpreendidos por saber que representantes desta perspetiva eram também cientistas considerados "modernos", como Kepler e Copérnico. Para além do próprio Newton, aliás.

De facto, se é verdade que Newton triunfou sim, simbolicamente, sobre Goethe, é também verdade que os alferes do
1. "Hegel aveva colto, con straordinaria precisione, questa centralità nel mondo magico, del tema della significatività universale: ogni particolarità diventa significativa. $\mathrm{Ci}$ sono solo significati. Ogni connessione è possibile, e il mondo è assolutamente pieno di connessioni. Tutto è possibile. Dietro a ogni oggetto o parola o gesto si nasconde un segreto." ROSSI, Paolo. Il tempo dei maghi. Rinascimento e modernità, 2006, p. 38.

2. BRUNO, Giordano, Opere magiche, 2000.

3. Idem. "De vinculis in genere", 2000.

4. ROSSI, Paolo. Il tempo dei maghi. Rinascimento e modernità, 2006. 
5. Ibidem, p. 20-21.

6. Cf. WHITE, Michael. Isaac

Newton: The Last Sorcerer, 1999.

7. ELIADE, Mircea.

Fragmentarium, 2008, p. 43. progresso esquecem (ou fingem esquecer) que o cientista inglês não era apenas um "cientista" como nós o entendemos hoje. Assim como Kepler se insere em um contexto de filosofia hermética que influencia fortemente as suas teorias, não obstante isso não se encontre nos livros de filosofia e de história (como evidencia o já citado Paolo Rossi ${ }^{5}$ ), Newton conhecia e praticava a alquimia, tão seriamente quanto a ciência ${ }^{6}$. Assim, os dois intelectuais, divididos no campo da Modernidade, encontram-se no terreno do dito esoterismo: ambos os estudiosos conheciam e baseavam as próprias teorias em uma visão do mundo mágica, não obstante terem posteriormente tomado diferentes caminhos.

Desta maneira, julgamos que existe outra forma de entrar na época moderna, seguindo o invisível fil rouge da magia, em vez do da ciência.

Escrevia Nietzsche que as praças de Europa estão cheias de estátuas de Goethe, mas que na cultura ocidental já não se encontra nada dele. Porém, a história do pensamento é imprevisível e as ideais exiladas sempre encontram maneira de voltar, a maioria das vezes nos lugares e nos tempos mais inesperados.

Os últimos anos do século XIX e as primeiras décadas do século xx conhecem um revivalismo das ciências ocultas sem precedentes, em que a visão mágica do mundo regressa com uma força explosiva, como o grande recalcamento da história do pensamento humano.

É suficiente pensar no número de seitas esotéricas que se formaram no final do século XIX para ter uma ideia da importância que teve o esoterismo naquela época. Em 1866 houve a fundação da Societas Rosicruciana in Anglia por Robert Wentworth Little, da qual faziam parte também William Wynn Westcott e William Robert Woodman. Os últimos dois, Westcott e Woodman, foram dois dos três fundadores em 1888 da Golden Dawn (Ordem Hermética da Aurora Dourada). Em 1875 morre o mágico Eliphas Lévi, um dos principais ocultistas do século XIX, nasce o controverso feiticeiro Aleister Crowley (que fará parte também da Golden Dawn) e a Sociedade Teosófica começa a sua aventura, graças a madame Blavatsky.

Mircea Eliade, o historiador das religiões romeno, afirma que, nas épocas em que a mística e a metafísica são esquecidas e combatidas, triunfam a mistagogia e o pseudo-ocultismo e quem já não acredita mais no Mistério, crê no mesmerismo, na maçonaria e no espiritismo ${ }^{7}$. O Iluminismo, elegendo a razão como novo e único deus da Humanidade, tinha banido o mistério da vida, deixando assim um vazio significativo na alma humana. Foi o irracionalismo a ocupar o lugar que a racionalidade, sozinha, já não podia preencher.

Assim, nos "salões bons" da burguesia inglesa, começam a registar-se presenças estranhas, espíritos vindos do além que 
agitam mesas e enviam mensagens misteriosas para serem interpretadas, e intelectuais, professores e bons burgueses relacionam-se em fraternidades esotéricas, praticando ritos ocultos no segredo de templos antigos.

As ideias esquecidas estavam a seguir o seu próprio curso, mexendo outra vez os peões da história.

\section{Fernando Pessoa, um astrólogo em Lisboa}

Leon Surette, professor na Western University of Canada, estudou a relação entre alguns intelectuais contemporâneos e a cultura oculta. No livro The birth of the Modernism ${ }^{8}$, pôs em destaque as raízes esotéricas das obras de Ezra Pound, Thomas Stearns Eliot e William Butler Yeats. Contudo, não é difícil individuar em outros escritores modernistas muito célebres traços de esoterismo: um dos membros mais famosos da Societas Rosicruciana in Anglia, por exemplo, foi o escritor austríaco Gustav Meyrink, antes de se converter ao Budismo, enquanto pertenciam à Golden Dawn, para além do já citado William Butler Yeats, os escritores Arthur Machen e Bram Stocker.

Em Portugal, o primeiro tradutor das obras teosóficas - que influenciarão de maneira determinante a sua produção - foi Fernando Pessoa. Podemos considerar o poeta português, de facto, como parte daquele fil rouge que liga a Weltanschanung renascentista ao pensamento moderno, como tentaremos demonstrar.

Não obstante muitas tentativas terem sido feitas para "liquidar" a produção esotérica de Pessoa como uma das blagues típicas do decifradores de charadas - como ele próprio se definiu - julgamos que para perceber melhor alguns dos aspectos da sua poética é necessário não esquecer que Fernando Pessoa estava interessado, desde uma idade muito precoce ${ }^{9}$, em assuntos esotéricos e que muitos dos fragmentos que nos deixou na arca tratam este tema. Geralmente, quando se fala de Fernando Pessoa como mágico, astrólogo e estudioso de ciência hermética é preciso lutar contra um certo ceticismo e uma velada ironia, se bem que já muitos e valentes investigadores - como António Quadros, Dalila Pereira da Costa, Yvette Centeno, Paulo Cardoso, José Augusto Seabra - tenham provado a importância fundamental que este assunto possui na produção pessoana. É também significativo o número elevado de livros relacionados com temáticas esotéricas que se encontram na sua biblioteca pessoal $^{10}$ e que demonstram quanto era genuíno o entusiasmo que o escritor sentia por estas temáticas. Para além disso,
8. SURETTE, Leon. The birth of the Modernism. Ezra Pound, T.S. Eliot, W.B. Yeats, and the Occult, 1993.

9. Yvette Centeno supôs que o primeiro interesse de Fernando Pessoa por temáticas ocultistas remontaria ao ano 1906 (Cf. PESSOA, Fernando. Fernando Pessoa e a Filosofia Hermética - Fragmentos do espólio, 1985, p. 9) e, recentemente, também Manuel Gandra (PESSOA, Fernando. Hermetismo e iniciação, 2015, p. 13) confirmou a hipótese de uma paixão muito precoce do poeta, chegando a individuar em 1904 a origem das primeiras leituras de esoterismo.

10. A digitalização completa dos livros que atualmente compõem a biblioteca pessoal do poeta está disponível online: http:// casafernandopessoa.cm-lisboa. pt/bdigital/index/index.htm 
11. PESSOA, Fernando.

"Primeiro Fausto". Poemas

Dramáticos, 1952, p. 76.

12. BAUDELAIRE, Charles. I

Fiori del Male, 2004, p. 66.

13. PESSOA, Fernando. Fernando

Pessoa e a Filosofia Hermética -

Fragmentos do espólio, 1995 , p. 37-38. a visão do mundo que está por detrás da produção poética de Fernando Pessoa mostra com clareza a forte influência de uma Weltanschaunng mágica, de que temos falado até agora.

Caso a ciência esqueça o lado mágico e misterioso do mundo, são os poetas que devem desvelar a essência secreta da natureza. No Fausto pessoano, que foi como para o Fausto goethiano uma das obras em que o poeta trabalhou durante toda a vida, manifesta-se o pensamento simbólico que permeia a sua poética: "Ah, tudo é símbolo e analogia!" 11 exclama a voz sem rosto do poema, tentando detectar o mistério do universo. O mundo é uma floresta de símbolos, como ensinava Baudelaire no célebre poema "Correspondance", em que se podem intuir infinitas ligações.

La Nature est un temple où de vivants piliers Laissent parfois sortir de confuses paroles; L'homme y passe à travers des forêts de symboles Qui l'observent avec des regards familiers.

Comme de long échos qui de loin se confondent Dans une ténébreuse et profonde unité, Vaste comme la nuit et comme la clarté,

Les parfums, les couleurs et les sons se répondent. ${ }^{12}$

A natureza, cheia de mistério, fala um idioma familiar, mas ao mesmo tempo desconhecido, porque se exprime através de símbolos. A linguagem simbólica, como afirma Pessoa, dirige-se à inteligência analógica e permite entender através da intuição verdades de ordem superior - ao contrário das palavras, concebidas para compreender apenas o grau mais superficial da realidade:

Todos os symbolos e ritos dirigem-se, não á intelligencia discursiva e racional, mas á intelligencia analogica. Porisso não ha absurdo em se dizer que, ainda que se quizesse revelar claramente o occulto, se não poderia revelar, por não haver para elle palavras com que se diga. O symbolo é naturalmente a linguagem das verdades superiores á nossa intelligencia, sendo a palavra naturalmente a linguagem d'aquellas que a nossa intelligencia abrange, pois existe para as abranger. ${ }^{13}$

A poética de Baudelaire, como a de Pessoa, põe em destaque o tema da analogia universal, a profonde unité que liga, em uma misteriosa rede de relações, todas as coisas, animadas e inanimadas, da natureza. Nesse caso, não é importante saber se Baudelaire subentende uma relação de tipo vertical e transcendente entre macro e microcosmo, como está subentendida no pensamento pessoano, ou se a sua rede de correspondências se desenvolve em um nível exclusivamente horizontal, pondo em ligação apenas um grau da realidade. É suficiente notar que a 
Natureza, que o poeta escreve com a letra inicial maiúscula, não está personalizada mas sacralizada: "La Nature est un temple" em que está sintetizado o cosmos inteiro, entendido como um ser vivente. O Poeta é o único que possui a capacidade de compreender a linguagem das correspondências universais. O olhar poético e simbólico contrapõe-se, assim, ao método científico que tudo analisa e divide, sem nunca alcançar a compreensão verdadeira da essência do fenômeno, que só se pode entender através de uma atitude capaz de captar a profunda unidade de todas as coisas. Uma disposição de alma, portanto, que permite a Pessoa - e ao Poeta em geral -desvelar no imperceptível, nas coisas mais banais e diárias, the poetic soul of the universe ${ }^{14}$.

Em um dos fragmentos com o nome "The way of the serpent", Pessoa individua três camadas da realidade, entre as quais há uma relação de correspondência exata, em que

tudo que se dá numa camada se reflecte e figura em outra. É este o principio fundamental de toda a ciência secreta, e assim o representou o Hermes Trismegistos na fórmula, o que está em cima é como o que está em baixo, e o que está em baixo é como o que está em cima. ${ }^{15}$

Como já dissemos, a máxima hermética exprime a possibilidade de unir em uma rede de analogias todos os entes do mundo entre si e afirma a conexão entre esferas superiores e esferas inferiores do cosmos. Pessoa prossegue o fragmento afirmando que o princípio fundamental de Hermes Trismegistos explica por qual motivo a astrologia consegue ler nas estrelas o destino do indivíduo: é justamente porque os aspectos dos planetas que estão em relação com o momento do nascimento, ou com outros eventos significativos da vida, possuem um significado simbólico também no mundo terreno que se pode reconhecer no céu aquilo que se encontra na terra.

No espólio pessoano, há traços evidentes de uma atividade astrológica muito intensa: cerca de 2.000 documentos ${ }^{16}$ são dedicados à redação de textos astrológicos, horóscopos, cálculos astrais e assim por adiante, e demonstram um conhecimento profundo dos princípios da matéria, digno de um especialista. De fato, entre os livros que compõem a biblioteca de Pessoa há obras astrológicas fundamentais, como os manuais de Alan Leo, alguns textos de H. S. Green e de Sepharial; Bailey, Astrology and birth control; Charles E. O. Carter, Symbolic directions in modern astrology; Robert Fludd, Traité d'Astrologie générale; George Wilde, Your destiny and the stars: the inequalities of man's lot and the only logical conception of it e muitos outros.

O interesse de Pessoa pela astrologia remontaria a 1915 - ano em que o poeta está também ocupado na tradução das obras teosóficas, obras que o levarão a uma crise intelectual
14. Idem. Páginas Íntimas e de Auto-Interpretação, 1966, p. 13.

15. Idem. Fernando Pessoa e a Filosofia Hermética - Fragmentos do espólio, 1995, p. 32.

16. PESSOA, Fernando. Cartas astrológicas, 2011, p. 10. 
17. Em uma carta a SáCarneiro, de 1915, Pessoa ao falar da Teosofia escreve: "O carácter extraordinariamente vasto desta religião-filosofia; a noção de força, de domínio, de conhecimento superior e extra-humano que ressumam as obras teosóficas, perturbaramme muito." Idem. Escritos Íntimos, Cartas e Páginas Autobiográficas, 1986, p. 122.

18. A reconstrução da relação e da correspondência entre Crowley e Pessoa podem ser encontrados no livro: PESSOA, Fernando e CROWLEY, Aleister. Encontro Magick. Lisboa: Assírio \& Alvim, 2010. Para determinar a influência de Crowley sobre a produção pessoana, vejam-se os ensaios de Marco Pasi, em particular: PASI, Marco. Aleister Crowley and the Temptation of Politics, 2014.

19. PESSOA, Fernando. Cartas astrológicas, 2011, p. 100. quase sem precedentes ${ }^{17}$-, quando aparece pela primeira vez o nome de Raphael Baldaya, o heterônimo astrólogo e ocultista. É atribuído a Baldaya um tratado de astrologia, New Theory of Astrological Periods, e outros textos de caráter esotérico, como o Tratado da negação e os Princípios de metafísica esotérica - em que se encontra uma interessante crítica à própria Teosofia - e alguns fragmentos relacionados com as Trovas do sapateiro e profeta Bandarra, acerca de uma interpretação esotérica do sebastianismo e do Quinto Império.

O número de mapas astrais que se encontra no espólio é algo impressionante: tentando descobrir analogias entre personagens, eventos históricos, mas também entre escritores célebres e ele próprio, Pessoa redigiu os horóscopos de Shakespeare, Goethe, Dante Gabriel Rossetti, Hugo, Chopin, Wilde, Dickens e Byron; de figuras políticas como Napoleão Bonaparte, Vittorio Emanuele III, Benito Mussolini, António de Oliveira Salazar e também D. Sebastião; e, enfim, como de cada coisa que tenha uma data de início se pode calcular o horóscopo, também a revista Orphen e Portugal possuem um.

Entre os horóscopos redigidos por Pessoa, há também o de Aleister Crowley, ocultista que, como já recordámos, pertencia à Golden Dawn e que manteve com o poeta português uma correspondência cerrada, antes do célebre encontro em Lisboa e do fictício suicídio do mágico em Cascais. Foi mesmo por Pessoa ter encontrado um erro no mapa astrológico de Crowley, que se encontra na edição do livro The confessions of Aleister Crowley de 1929 e que ainda está presente na biblioteca do poeta, que os dois intelectuais se conheceram ${ }^{18}$.

Contudo, para Pessoa calcular as influências astrais não era apenas uma brincadeira ou um passatempo sem fins específicos. No caso de Shakespeare, por exemplo, é evidente que o poeta, ao interpretar o seu mapa astrológico, está tentando achar coincidências entre o colega inglês e ele próprio - como bem põe em destaque Paulo Cardoso. Haveria, nos dois horóscopos, fortes analogias, indicando que o supra-Camões seria o descendente direto do grande dramaturgo:

Algumas correntes de astrologia ligadas à reencarnação
sugerem que este tipo de coincidência pode indicar uma
ligação kármica (ou uma sequência de encarnações) entre
personalidades. ${ }^{19}$

A tentativa de construir - melhor, descobrir - uma descendência kármica entre si e os seus ilustres predecessores continua, estendendo-se até Milton e Baudelaire. O poeta queria estabelecer, às vezes com sucesso, as conjunções planetárias no momento do nascimento e da morte destes artistas, encontrando uma linha direta do destino - isto é, as indicações exatas de 
uma reencarnação - que teria passado por William Shakespeare para chegar até ele. No dramaturgo inglês, Fernando Pessoa via a personificação do gênio e do grau mais elevado da faculdade poética, como indica em um célebre fragmento sobre os quatro níveis da expressão poética, desde o mais superficial ao mais elaborado. Se o poeta principiante se limita a escrever as suas emoções, reelaborando apenas o próprio sentimento individual, no segundo grau já se encontrará uma abertura a horizontes temáticos diferentes e começará a usar ativamente a imaginação. No terceiro estádio, haverá um primeiro aceno de despersonalização e de perda de individualidade, tendo em vista uma maior extensão intelectual:

O terceiro grau da poesia lírica é aquele em que o poeta, ainda mais intelectual, começa a despersonalizar-se, a sentir, não já porque sente, mas porque pensa que sente; a sentir estados de alma que realmente não tem, simplesmente porque os compreende. Estamos na antecâmara da poesia dramática, na sua essência íntima. O temperamento do poeta, seja qual for, está dissolvido pela inteligência. A sua obra será unificada só pelo estilo, último reduto da sua unidade espiritual, da sua coexistência consigo mesmo. ${ }^{20}$

O último nível que o poeta pode alcançar é o da poesia dramática, em que a despersonalização é total e perfeita:

O quarto grau da poesia lírica é aquele, muito mais raro, em que o poeta, mais intelectual ainda mas igualmente imaginativo, entra em plena despersonalização. Não só sente, mas vive, os estados de alma que não tem directamente. Em grande número de casos, cairá na poesia dramática, propriamente dita, como fez Shakespeare, poeta substancialmente lírico erguido a dramático pelo espantoso grau de despersonalização que atingiu. ${ }^{21}$

Já começamos a perceber qual é a motivação que levava Fernando Pessoa a procurar uma descendência astral entre si mesmo e William Shakespeare. Se o grau máximo que um poeta pode aspirar a alcançar é a despersonalização total da alma individual, então quem mais de Fernando Pessoa conseguiu essa proeza? Com a criação dos heterônimos, o poeta deu vida a um "great act of intellectual magic, a magnum opus of the impersonal creative power" "22. Alberto Caeiro, Álvaro de Campos e Ricardo Reis representam as etapas de uma transmutação alquímica da alma poética, como indica claramente o termo magnum opus utilizado por Pessoa, com a plena consciência de quem estudava as matérias herméticas.

Naturalmente, também os heterônimos têm mapas astrológicos significativos. Como afirma Paulo Cardoso - não obstante ter lutado contra os preconceitos, que já referimos, antes que a
20. Idem. Páginas de Estética e de Teoria Literárias, 1966 , p. 67.

21. Ibidem, p. 67.

22. LOPES, Teresa Rita. Pessoa por Conhecer - Textos para um Novo Mapa, 1990, p. 249. 
23. PESSOA, Fernando. Cartas astrológicas, 2001, p. 9.

24. Ibidem, p. 82.

25. WIRTH, Oswald. O

simbolismo hermético na sua relação

com a Franco-maçonaria, 2004, p. 39. sua teoria fosse aceita - a pratica astrológica, como a hermética, tiveram uma forte influência na definição da poética pessoana:

Ao longo destes 34 anos em que tenho lidado com a prática da astrologia, senti o peso do preconceito e da ignorância. Muitas vezes, quando abordei o tema da astrologia de Fernando Pessoa, percebi que este assunto era olhado de soslaio, com uma espécie de aceitação condescendente. [...] Com o passar dos anos, consegui reunir as provas de que a astrologia tinha servido de veículo de conhecimento e de filosofia orientadora ao homem, ao escritor; e que ela tinha sido, também, um instrumento útil, estrutural e até determinante na criação dos heterónimos. ${ }^{23}$

Ao analisar os horóscopos de Caeiro, Reis e Campos, descobrimos logo que possuem um elemento astral em comum muito significativo, que não é de modo nenhum casual: Pessoa tinha tentado várias combinações, com datas de nascimento e horários diferentes, antes de encontrar a conjunção planetária certa. Os três heterônimos "têm Mercúrio (símbolo dos irmãos) exatamente na mesma Casa astrológica, a VIII" - Casa que "remete para o oculto, para a transcendência, para as iniciações secretas"24.

Mercúrio, em astrologia, governa a esfera do pensamento e está relacionado com o deus grego Hermes, mensageiro dos deuses (Platão, no Crátilo, faz derivar o nome Hermes do termo $\dot{\varepsilon} \varrho \mu \eta v \varepsilon i \alpha$, que significa interpretação. A hermenêutica, isto é, a prática filosófica da interpretação, teria a sua raiz na mesma palavra). Uma das características de Hermes é de ser psicopompo, ou seja, de acompanhar os defuntos no mundo dos infernos, sendo uma espécie de guia das almas. Na literatura hermética, Hermes tem um papel de especial relevância: corresponde ao deus egípcio Thot, escriba dos deuses, divindade relacionada com a sabedoria e a magia, e que Platão indica como pai da escrita. Em seguida, Hermes/Thot foi identificado como o autor do Corpus Hermeticum, ou seja, Hermes Trismegistos, cujo epíteto elogiador significa "três vezes grande". Em latim, é chamado Mercurius ter Maximus e é o protetor da astrologia, da alquimia, das ciências ocultas e da iniciação em geral.

Em alquimia, o mercúrio como elemento químico tem uma importância fundamental:

O Mercúrio dos Sábios representa, por excelência, o estímulo de toda vitalidade, o fluido universal que penetra todas as coisas e une a todos os seres com os laços de uma segreda simpatia. É pelo seu intermédio que se realizam as operações mágicas e mais especificamente os milagres da medicina oculta. ${ }^{25}$

Portanto, quando Pessoa tenta fazer coincidir nos horóscopos dos seus heterônimos Mercúrio na Casa VIII (e faz isso 
conscientemente, pois o poeta conhecia muito bem o significado deste planeta na filosofia hermética), é para "criar uma espécie de fraternidade astral' 26 e iniciática entre eles e o seu próprio criador: "Pessoa, ele mesmo, tinha como planeta regente Mercúrio, sendo pois frater desta congregação" 27 . Para além de estabelecer uma natural inclinação para as ciências ocultas, esta concordância mercurial indica alquimicamente que nos heterônimos se exprime a totalidade das possibilidades latentes da sua matéria prima, isto é, do poeta Pessoa. Paulo Cardoso pôs também em evidência que o ascendente de cada heterônimo pertence a um dos quatros elementos naturais (água, fogo, terra e ar) e que portanto se pode concluir que

a família heteronímica detinha a plenitude dos princípios fundamentais da filosofia ancestral; e que constituía, em suma e simbolicamente, algo de absoluto e indivisível. Os quatro poetas eram, em si, todo um universo. ${ }^{28}$

O que importa no presente ensaio não é tanto atestar e avaliar as capacidades práticas e os conhecimentos de Pessoa como astrólogo (trabalho que Paulo Cardoso já fez com muita competência no seu estudo citado várias vezes ao longo destas páginas), mas sim demostrar como ele retoma de maneira consciente uma sabedoria antiga e utiliza as suas ferramentas para dar sentido à sua poética. A concepção do mundo pessoana remonta a uma tradição mágica em que todos os entes estão entrelaçados entre si, formando uma rede de significados que permite, como já dissemos, interpretar o cosmos de maneira simbólica e encontrar a unidade que se esconde por detrás da fragmentação da vida. Nada no universo morre, porque existem apenas laços que se dissolvem e voltam a aparecer em outras combinações ${ }^{29}$ - justificação pela qual Pessoa pôde calcular, por exemplo, as influências astrais no mapa astrológico de Shakespeare, encontrando analogias consigo próprio.

Naturalmente, isto não quer dizer que a chave de leitura mágico-astrológica seja a única possível para interpretar a obra pessoana. Pelo contrário, ao descobrirmos também este aspecto, percebemos quantas camadas - além da literária - tem a criação poética do escritor português e quanto é necessário evitar excluir algumas delas só em função de preconceitos superficiais, que impedem uma compreensão total e completa do seu pensamento. Evidentemente, seria impossível exaurir o universo esotérico pessoano no espaço de poucas páginas - também não era esta a nossa intenção. Contudo, queremos afirmar que a constelação-Pessoa inclui também o Pessoa-astrólogo, o mágico, o ocultista e o filosofo hermético. Uma consideração mais atenta e científica destas temáticas permitiria avançar na interpretação da obra pessoana, devolvendo finalmente valor a um dos seus aspectos mais subestimados e menosprezados.
26. PESSOA, Fernando. Cartas astrológicas, 2001, p. 14

27. Ibidem, p. 82.

28. Ibidem, p. 14.

29. BRUNO, Giordano, Opere magiche, 2000, p. 231. 


\section{Referências}

BAUDELAIRE, Charles. I Fiori del Male. Roma: Newton \& Compton, 2004.

BRUNO, Giordano. Opere magiche. Milano: Adelphi, 2000.

ELIADE, Mircea. Fragmentarium. Milano: Jaca Book, 2008.

LOPES, Teresa Rita. Pessoa por Conhecer - Textos para um Novo Mapa. Lisboa: Estampa, 1990.

PASI, Marco. Aleister Crowley and the Temptation of Politics. London: Routledge, 2014.

PESSOA, Fernando. Cartas astrológicas. Lisboa: Bertand editora, 2011.

Escritos Íntimos, Cartas e Páginas Autobiográficas. Lisboa: Europa-América, 1986.

Fernando Pessoa e a Filosofia Hermética - Fragmentos do espólio. Lisboa: Presença, 1985.

espólio, 1995.

Fernando Pessoa e a Filosofia Hermética - Fragmentos do . Hermetismo e iniciação. Sintra: Zéfiro, 2015.

_. Páginas de Estética e de Teoria Literárias. Lisboa: Ática, 1966.

. Páginas Íntimas e de Autointerpretação. Lisboa: Ática, 1966. Poemas Dramáticos. Lisboa: Ática, 1952.

PESSOA, Fernando; CROWLEY, Aleister. Encontro Magick. Lisboa: Assírio \& Alvim, 2010.

ROSSI, Paolo. Il tempo dei maghi. Rinascimento e modernità. Milano: Raffaello Cortina, 2006.

SURETTE, Leon. The birth of the Modernism. Ezra Pound, T.S. Eliot, W.B. Yeats, and the Occult. Montreal: McGill-Queen's University Press, 1993.

WHITE, Michael. Isaac Newton: The Last Sorcerer. New York: Basic Books, 1999.

WIRTH, Oswald. O simbolismo hermético na sua relação com a Franco-maçonaria. Lisboa: Hugin Editores, 2004. 